\title{
Cell viability, collagen synthesis and cytokine expression in human osteoblasts following incubation with generated wear particles using different bone cements
}

\author{
CHRISTOPH SCHULZE ${ }^{1,2}$, KATRIN LOCHNER ${ }^{1}$, ANIKA JONITZ ${ }^{1}$, ROBERT LENZ ${ }^{1}$, \\ OLIVER DUETTMANN $^{3}$, DORIS HANSMANN ${ }^{1}$ and RAINER BADER ${ }^{1}$ \\ ${ }^{1}$ Department of Orthopaedics, University Medicine Rostock, D-18057 Rostock; ${ }^{2}$ Department of Orthopaedic Surgery, \\ Armed Forces Hospital, Bundeswehr, D-26655 Westerstede; ${ }^{3}$ Department of Applied Science and Mechatronics, \\ University of Applied Science Munich, D-80335 Munich, Germany
}

Received February 26, 2013; Accepted April 23, 2013

DOI: $10.3892 /$ ijmm.2013.1383

\begin{abstract}
In total hip arthroplasty, wear particles generated at articulating surfaces and interfaces between bone, cement and implants have a negative impact on osteoblasts, leading to osteolysis and implant loosening. The aim of this experimental study was to determine the effects of particulate wear debris generated at the interface between straight stainless steel hip stems $\left(\right.$ Exeter $\left.^{\circledR}\right)$ and three different bone cements (Palacos ${ }^{\circledR} \mathrm{R}$, Simplex ${ }^{\mathrm{TM}} \mathrm{P}$ and Cemex ${ }^{\circledR}$ Genta) on cell viability, collagen synthesis and cytokine expression in human osteoblasts. Primary osteoblasts were treated with various concentrations of wear particles. The synthesis of procollagen type I and different cytokines was analysed, and markers for apoptosis and necrosis were also detected. The cytokine synthesis rates in the osteoblasts were initially increased and varied, depending on incubation time and particle concentration. Specific differences in the synthesis rates of interleukin (IL)-6, IL-8, vascular endothelial growth factor (VEGF) and monocyte chemotactic protein-1 (MCP-1) were observed with the different bone cements examined. The negative effect of the particles on the synthesis of procollagen type I and increased rates of cell apoptosis and necrosis were observed with all three cements analysed. Our present data suggest that wear particles from the interface between the total hip stem and bone cement have a significant effect on viability, cytokine expression and collagen synthesis in human osteoblasts, depending on the bone cement used.
\end{abstract}

\section{Introduction}

Aseptic implant loosening is the most common cause of revision of total hip endoprosthesis (1). It is mainly caused by

Correspondence to: Dr Christoph Schulze, Department of Orthopaedics, University Medicine Rostock, Doberaner Str. 142, D-18057 Rostock, Germany

E-mail: christoph.schulze@med.uni-rostock.de

Key words: aseptic implant loosening, bone cement, wear particles, osteoblasts, cytokine wear particles generated at the articulating surfaces of implant components and at the interface between implant and bone or implant and bone cement (2). The biological effects of wear particles depend on the implant material, as well as on the amount, shape and composition of the particles (3). Generally, elongated particles generate more pro-inflammatory responses than round particles, and there is a growing consensus that metallic particles generate more pro-inflammatory responses than polymers or ceramics (3). They have to be $<10 \mu \mathrm{m}$ in diameter to be phagocytosable, leading to specific cytokine release and a decrease in osteoblast function and an increase in osteoclast activity (3). It is well known that metallic wear particles influence the production of cytokines, such as interleukin (IL)-6 and IL-8, monocyte chemotactic protein-1 (MCP-1), fibroblast growth factor (FGF) and vascular endothelial growth factor (VEGF) (4-7). IL-6 is important in bone metabolism, having a positive effect on the differentiation of progenitor cells into osteoblasts and an anti-apoptotic effect, additionally (8). Through another signalling pathway, IL-6 can also stimulate the differentiation of osteoclasts (8); in combination with the macrophage colony-stimulating factor (MCSF), the differentiation and activity of osteoclasts is increased (9).

Furthermore, it is also known that ultrahigh molecular weight polyethylene (UHMWPE) particles inhibit the proliferation and differentiation of pre-osteoblasts and bone marrow cells in vitro (10). Nowadays, the age of the patients is also considered to play a role in the effects of wear particles (11). Hereby, many attempts to reduce the incidence of implant loosening aim at optimising the material and surface of implants, as well as their fixation in the bone stock. Therefore, a variety of bone cements are available for the cemented fixation of total hip endoprosthesis. To date, little attention has been paid to the biological effects of bone cement wear particles produced by abrasive wear or relative motion at bone cement interfaces (12). In this context, only a few studies have compared the biological effects of clinically relevant wear particles of different bone cements on human histiocytes and macrophages $(4,12)$.

Polymethylmethacrylate (PMMA) is the main component of bone cement and does not induce apoptosis in osteoclasts (13). Particles of hydroxyapatite, however, can induce 
apoptosis in osteoclasts (14). Zambonin et al (15) examined the effect of PMMA on human osteoblasts. It was found that PMMA inhibits cell proliferation and collagen synthesis. They further observed an increased release of IL- 6 and osteocalcin, which in turn increases the activity of osteoclasts and thus complicates the integration of implants into the bone stock (15). In addition, Gough and Downes (16) demonstrated that, depending on the concentration, methacrylate polymers exert a pro-apoptotic effect on osteoblasts. Willert et al (17) observed the necrosis of bone tissue surrounding cemented implants. Ciapetti et al $(18,19)$ observed necrosis and apoptosis in HL-60 cells, a human promyelocytic cell line, as well as in MG-63 cells, a human osteosarcoma cell line, following incubation with different bone cements.

The effect of wear particles generated at the interface between bone cement $\left(\right.$ Palacos $\left.{ }^{\circledR} \mathrm{R}\right)$ containing zirconium dioxide $\left(\mathrm{ZrO}_{2}\right)$ and total hip stems made of alloys of cobalt-chromiummolybdenum and titanium was examined in our previous study [Lenz et al (20)]. Here, human osteoblasts showed decreased viability and procollagen type I synthesis, as well as a materialand time-dependent release of IL-6 and IL-8. Additionally, an inhibited release of cytokine and procollagen type I synthesis depending on the concentration of the cement was observed. In particular, wear particles generated from cobalt-chromium stems had a negative effect on the viability and proliferation of human osteoblasts, whereas $\mathrm{ZrO}_{2}$ particles did not have a significant effect when compared to the control sample (20).

However, cell viability and cytokine release by primary osteoblasts following incubation with wear particles generated at the interface between total hip stems and different bone cements have not been investigated thus far. Hence, the aim of this experimental study was to determine the viability and proliferation of human osteoblasts following incubation with wear particles generated with 3 commercially available bone cements of different compositions. In our previous studies [Lochner et al (21) and Lenz et al (20)], we investigated the effect of several metallic wear debris on primary osteoblasts. In our present in vitro study, we evaluated the effect of bone cement particles on cytokine expression, particularly IL-6, IL-8, FGF, VEGF and MCP-1, on the synthesis of procollagen type I and on the occurrence of apoptosis and necrosis in osteoblasts $(20,21)$.

\section{Materials and methods}

Isolation and cultivation of human primary osteoblasts. Human femoral heads were obtained from 3 patients ( 2 male donors, mean age, $69.5 \pm 4.5$ years; 1 female donor, 47 years) undergoing primary total hip replacement due to primary osteoarthritis. The bone samples were collected after patient consent was obtained and following approval by the local ethics committee (A 2010-10).

For the isolation and cultivation of human osteoblasts, cancellous bone was harvested from the inside of the femoral heads, washed 3 times with phosphate-buffered saline (PBS) (PAA Laboratories GmbH, Coelbe, Germany) and cut into small pieces. Cells from different donors were kept separately.

Subsequently, the cancellous bone was treated with Dulbecco's modified Eagle's medium (DMEM; Biochrom AG, Berlin, Germany) containing collagenase A and dispase (both from Roche Diagnostics GmbH, Mannheim, Germany) at a ratio of $1: 2: 1$ at $37^{\circ} \mathrm{C}$ for $3 \mathrm{~h}$. The cell suspension was filtered through a cell strainer (pore size, $70 \mu \mathrm{m}$; Nunc, Wiesbaden, Germany) and centrifuged at $118 \mathrm{xg}$ for $10 \mathrm{~min}$. The resulting cell pellet was resuspended in complete medium containing $10 \%$ fetal bovine serum (FBS), $1 \%$ amphotericin B, $1 \%$ penicillin-streptomycin and $1 \%$ HEPES buffer (all from Gibco ${ }^{\oplus}$-Invitrogen, Darmstadt, Germany) and transferred into $25 \mathrm{~cm}^{2}$ culture flasks with $8 \mathrm{ml}$ of complete medium supplemented with ascorbic acid (final concentration, $50 \mu \mathrm{g} / \mathrm{ml}$ ), $\beta$-glycerophosphate (final concentration, $10 \mathrm{mM}$ ) and dexamethasone (final concentration, $100 \mathrm{nM}$ ) (all from Sigma, Seelze, Germany). Cells were incubated in a humidified atmosphere of $5 \% \mathrm{CO}_{2}$ and $37^{\circ} \mathrm{C}$. The cell culture medium was changed every second day to remove non-adherent cells. Cell proliferation was tracked microscopically. As cells reached $90 \%$ confluency, they were trypsinised and split at a ratio of 1:6.

Cell seeding and particle incubation. For all analyses, human osteoblasts $\left(3 \times 10^{3}\right.$ cells) were transferred to 96 -well culture plates and incubated in complete medium as mentioned above at $37^{\circ} \mathrm{C}$ and $5 \% \mathrm{CO}_{2}$. Subsequently, osteoblasts were incubated with different bone cement particles at 2 different concentrations $(0.1$ and $0.01 \mathrm{mg} / \mathrm{ml})$. The particles dropped to the bottom of the wells and came into contact with the adherent osteoblasts. After 2 and 4 days of incubation, supernatants were collected and stored at $-20^{\circ} \mathrm{C}$.

Generation and preparation of wear particles. Particles of three different commercially available bone cement products were used in this experimental setting. Wear particles were generated using a special test apparatus as previously described (2). With cyclic loading of $5 \mathrm{~Hz}$, a surface pressure of $2 \mathrm{MPa}$ and 3 million cycles, smoothly polished hip stems made of 316L stainless steel (type Exeter; Stryker GmbH, Duisburg, Germany) were rubbed against the cement mantles. The following cements were used in the production of cement mantles: Palacos R (Heraeus, Wehrheim, Germany), Cemex ${ }^{\circledR}$ Genta (Exactech, Kiel, Germany) and Simplex ${ }^{\mathrm{TM}} \mathrm{P}$ (Stryker GmbH). The composition of each type of cement is shown in Table I.

To determine the metal content of the generated debris of cement and metal particles, we treated $5 \mathrm{mg}$ of wear debris with $5 \mathrm{ml}$ nitric acid in an industrial microwave oven (MDS-2000; CEM; Kamp-Linfort, Germany) for $1 \mathrm{~h}$ to break down organic compounds. After cooling down at room temperature for $1 \mathrm{~h}$, the mixture was dissolved in $50 \mathrm{ml}$ distilled water in order to determine the metallic content through atomic absorption spectroscopy (AAS; SpectrAA-30 Zeeman; Varian, Darmstadt, Germany). AAS indicated the following average content of metal (iron) in $\mu \mathrm{g}$ for every $1 \mathrm{~g}$ of wear particles: $350.00 \mu \mathrm{g} / \mathrm{g}$ for Simplex P; $90.75 \mu \mathrm{g} / \mathrm{g}$ for Cemex Genta; and $2180.83 \mu \mathrm{g} / \mathrm{g}$ for Palacos R.

Pure PMMA polymer powder (Palacos R, referred to below as PMMA) and $\mathrm{ZrO}_{2}$ particles (Heraeus) were used as the reference particles. Five milligrams of each generated wear particles and commercially available reference particles were sterilized by the use of $\gamma$ radiation. Subsequently, a stock solution $(10 \mathrm{mg} / \mathrm{ml})$ was prepared by suspending the particles in $0.5 \mathrm{ml}$ sterile PBS (PAA Laboratories $\mathrm{GmbH}$ ). Further dilutions with cell culture medium created the final particle concentrations of 0.1 and $0.01 \mathrm{mg} / \mathrm{ml}(21)$. 
Table I. Content of used bone cements as described in a previous study (24).

\begin{tabular}{|c|c|c|c|c|}
\hline Cement & Polymer and monomer & Radiopaque agent & Antibiotic agent & Other components \\
\hline Palacos R & $\begin{array}{l}33.55 \text { g PMMA } \\
18.4 \text { g MMA }\end{array}$ & $\begin{array}{l}6.13 \mathrm{~g} \text { zirconium } \\
\text { dioxide }\end{array}$ & - & $\begin{array}{l}0.32 \mathrm{~g} \text { benzoyl-peroxide (BPO) } \\
1.4 \mathrm{mg} \text { chlorophyll } \\
0.38 \mathrm{~g} \mathrm{~N}, \mathrm{~N}-\text { dimethyl-p-toluidine }\end{array}$ \\
\hline Simplex P & $\begin{array}{l}29.4 \text { g MMA-styrene } \\
\text { copolymer } \\
6 \text { g PMMA, } 18.31 \mathrm{~g} \mathrm{MMA}\end{array}$ & $4 \mathrm{~g}$ barium sulphate & - & $\begin{array}{l}0.6 \mathrm{~g} \mathrm{BPO} \\
80 \mathrm{ppm} \text { hydroquinone } \\
0.48 \mathrm{~g} \mathrm{~N}, \mathrm{~N} \text {-dimethyl-p-toluidine }\end{array}$ \\
\hline Cemex Genta & $\begin{array}{l}33.11 \text { g PMMA } \\
\text { (3\% styrene) } \\
13.06 \text { g MMA }\end{array}$ & $4 \mathrm{~g}$ barium sulphate & $\begin{array}{c}1.69 \mathrm{~g} \\
\text { gentamicin sulphate }\end{array}$ & $\begin{array}{l}1.2 \mathrm{~g} \mathrm{BPO} \\
75 \mathrm{ppm} \text { hydroquinone } \\
0.24 \mathrm{~g} \mathrm{~N}, \mathrm{~N} \text {-dimethyl-p-toluidine }\end{array}$ \\
\hline
\end{tabular}

PMMA, polymethylmethacrylate. MMA, methylmethacrylate.

Procollagen type I (CICP) quantification. Procollagen type I (Metra ${ }^{\mathrm{TM}}$ CICP EIA kit; Quidel, Marburg, Germany) was detected in the supernatants using an enzyme-linked immunosorbent assay (ELISA) according to the manufacturer's instructions. Absorbance was measured at $405 \mathrm{~nm}$ using an Opsys MR ${ }^{\mathrm{TM}}$ microplate reader (Dynex Technologies, Denkendorf, Germany).

Quantification of cytokines. Osteoblast culture supernatants were analysed using a Bio-Plex Pro ${ }^{\mathrm{TM}}$ assay (Bio-Plex Pro Human Cytokines Group I 5-plex 1x96; Bio-Rad, Munich, Germany) in order to determine the expression of cytokines (IL-6, IL-8, FGF, VEGF and MCP-1). The Bio-Plex system permits the simultaneous detection of up to 100 different types of molecules in a single well of a 96-well microplate. The principle of the bead-based assay is similar to a sandwich immunoassay. The assay was performed according to the manufacturer's instructions. An antibody directed towards the desired cytokine target is covalently coupled to internally dyed beads. These coupled beads react with the sample, which contains the target biomolecule. Subsequently, a biotinylated detection antibody specific to an epitope different from that of the capture antibody is added to the assay, resulting in the formation of a sandwich of antibodies around the cytokine target. A streptavidin-phycoerythrin reporter complex is added to bind the biotinylated detection antibodies to the bead surface. The intensity of fluorescence was analysed in a Bio-Plex 200 System using Bio-Plex Manager software 4.1.1 (both from Bio-Rad).

Analysis of apoptosis and necrosis. Apoptosis and necrosis of the primary osteoblasts were determined after 2 days using the Cell Death Detection ELISA kit (Roche Diagnostics GmbH) according to the manufacturer's instructions. For necrosis, osteoblast culture supernatants were analysed. Apoptosis was detected in the cell lysates. Absorbance was measured at $490 \mathrm{~nm}$ using an Opsys $\mathrm{MR}^{\mathrm{TM}}$ microplate reader (Dynex Technologies).

Statistical analysis. Descriptive statistics [mean value, standard error of the mean (SEM)] were calculated for each data set. Statistical analysis was performed using one-way ANOVA (post hoc LSD). Significances of the respective protein data are based on the unstimulated control on day 2. To compare day 2 with day 4 , statistical analysis was performed using the Wilcoxon test for dependent variables. All P-values were the result of two-tailed statistical tests, with values of $\mathrm{P}<0.05$ considered to indicate a statistically significant difference. All data were stored and analysed using the statistics program SPSS version 15.0 (SPSS Inc., Chicago, IL, USA).

\section{Results}

Procollagen type I synthesis. The concentration of procollagen type $\mathrm{I}$ in the cell culture supernatants was determined (Fig. 1) in order to assess the synthesis activity of the human osteoblasts. Following incubation with bone cement particles, time- and concentration-dependent differences were observed. For all bone cements examined, a particle concentration of $0.1 \mathrm{mg} / \mathrm{ml}$ led to a significant decline in collagen synthesis after 2 days when compared to the control sample (Palacos R, $\mathrm{P}=0.013$; Simplex $\mathrm{P}, \mathrm{P}=0.017$; Cemex Genta, $\mathrm{P}<0.001)$. For pure $\mathrm{ZrO}_{2}$ particles, this effect was less pronounced $(\mathrm{P}<0.001)$. After 4 days of incubation at a particle concentration of $0.1 \mathrm{mg} / \mathrm{ml}$, a significant reduction in procollagen type I concentration $(\mathrm{P}<0.001)$ was observed with all the cement particles. In particular, a pronounced reduction was observed with Simplex P. Between days 2 and 4, Palacos R induced a less significant decline in the synthesis rate compared to the other bone cements $(\mathrm{P}<0.001)$. After 4 days of incubation with $\mathrm{ZrO}_{2}$ particles, the synthesis of procollagen type I in the osteoblasts did not differ significantly from that at 2 days of incubation. Nevertheless, the total concentration was still lower than the concentration of the day 2 control sample $(\mathrm{P}=0.005)$ (Fig. 1).

Even low concentrations of cement particles $(0.01 \mathrm{mg} / \mathrm{ml})$ had a negative effect on collagen type I synthesis, although this effect was not as pronounced as that induced by higher particle concentrations. After 2 days of incubation with $0.01 \mathrm{mg}$ of particles $/ \mathrm{ml}$, there were small cement-specific differences. The effects after 4 days of incubation with $0.01 \mathrm{mg} / \mathrm{ml}$ were similar to those observed at $0.1 \mathrm{mg} / \mathrm{ml}$. 
Table II. IL-6 synthesis in human osteoblasts following treatment with particles $(0.1$ and $0.01 \mathrm{mg} / \mathrm{ml}$; $\mathrm{n}=3)$ on days 2 and 4 .

\begin{tabular}{lcccc}
\hline & \multicolumn{2}{c}{$\begin{array}{c}\text { Day } 2 \\
\text { IL-6 content (relative to control on day 2) }\end{array}$} & $\begin{array}{c}\text { Day } 4 \\
\text { IL-6 content (relative to control on day 2) }\end{array}$ \\
\cline { 2 - 5 } Particle & $0.1 \mathrm{mg} / \mathrm{ml}(\%)$ & $0.01 \mathrm{mg} / \mathrm{ml}(\%)$ & $0.1 \mathrm{mg} / \mathrm{ml}(\%)$ & $0.01 \mathrm{mg} / \mathrm{ml}(\%)$ \\
\hline Palacos & $143 \pm 19$ & $101 \pm 3$ & $56 \pm 18^{\mathrm{a}}$ & $53 \pm 9$ \\
Simplex & $153 \pm 28$ & $148 \pm 19$ & $31 \pm 7^{\mathrm{a}}$ & $77 \pm 30$ \\
Cemex Genta & $269 \pm 115$ & $127 \pm 7$ & $23 \pm 4^{\mathrm{a}}$ & $84 \pm 36$ \\
PMMA & $413 \pm 258$ & $149 \pm 67$ & $32 \pm 9^{\mathrm{a}}$ & $79 \pm 28$ \\
ZrO & $125 \pm 15$ & $145 \pm 21$ & $58 \pm 17^{\mathrm{a}}$ & $52 \pm 11$ \\
Control & & & $57 \pm 14^{\mathrm{a}}$ \\
\hline
\end{tabular}

Supernatants were collected after 2 and 4 days of cultivation and analysed by Multiplex-ELISA. Data are presented as the means \pm SEM. Statistical analysis was performed using one-way ANOVA (post hoc LSD). Significance is based on the IL-6 content of the control on day 2. ${ }^{\text {a }}<0$.05. IL-6, interleukin-6; PMMA, polymethylmethacrylate; $\mathrm{ZrO}_{2}$, zirconium dioxide.

Table III. IL-8 synthesis in human osteoblasts following treatment with particles $(0.1$ and $0.01 \mathrm{mg} / \mathrm{ml} ; \mathrm{n}=3)$ on days 2 and 4 .

\begin{tabular}{|c|c|c|c|c|}
\hline \multirow[b]{2}{*}{ Particle } & \multicolumn{2}{|c|}{$\begin{array}{c}\text { Day } 2 \\
\text { IL-8 content (relative to control on day } 2 \text { ) }\end{array}$} & \multicolumn{2}{|c|}{$\begin{array}{c}\text { Day } 4 \\
\text { IL-8 content (relative to control on day 2) }\end{array}$} \\
\hline & $0.1 \mathrm{mg} / \mathrm{ml}(\%)$ & $0.01 \mathrm{mg} / \mathrm{ml}(\%)$ & $0.1 \mathrm{mg} / \mathrm{ml}(\%)$ & $0.01 \mathrm{mg} / \mathrm{ml}(\%)$ \\
\hline Palacos & $417 \pm 282$ & $97 \pm 11$ & $55 \pm 9$ & $51 \pm 7$ \\
\hline Simplex & $116 \pm 71$ & $114 \pm 3$ & $73 \pm 29$ & $71 \pm 16$ \\
\hline Cemex Genta & $155 \pm 44$ & $100 \pm 11$ & $42 \pm 13$ & $96 \pm 34$ \\
\hline PMMA & $354 \pm 217$ & $109 \pm 13$ & $67 \pm 30$ & $95 \pm 33$ \\
\hline $\mathrm{ZrO}_{2}$ & $136 \pm 23$ & $200 \pm 92$ & $60 \pm 16^{a}$ & $60 \pm 11$ \\
\hline Control & \multicolumn{2}{|c|}{$100 \pm 0$} & \multicolumn{2}{|c|}{$55 \pm 9$} \\
\hline
\end{tabular}

Supernatants were collected after 2 and 4 days of cultivation and analysed by Multiplex-ELISA. Data are presented as the means \pm SEM. Statistical analysis was performed using one-way ANOVA (post hoc LSD). Significance is based on the IL-8 content of the control on day 2. ${ }^{\text {a }}<<0.05$. IL-8, interleukin-8; PMMA, polymethylmethacrylate; $\mathrm{ZrO}_{2}$, zirconium dioxide.

\section{Determination of cytokine release by human osteoblasts}

$I L-6$ and $I L-8$. Bone cement particles induced an increased production of IL- 6 and IL- 8 by osteoblasts during the first 2 days (Tables II and III). A time-dependent effect was observed for all analysed bone cements, whereas differences in particle concentrations were only observed with Cemex Genta. IL-6 concentrations were decreased in all the particle samples after 4 days compared to the control on day 2 , which were significant with the $0.1 \mathrm{mg} / \mathrm{ml}$ particle treatments. Additionally, the IL- 6 concentration of the control on day 4 was significantly reduced compared to that observed on day 2 .

IL-8 expression showed an increase in the samples incubated with $0.1 \mathrm{mg} / \mathrm{ml}$ Palacos R and PMMA after 2 days. Following prolonged particle incubation, all samples demonstrated a decrease in IL-8 expression. At the lower Cemex Genta and PMMA concentrations $(0.01 \mathrm{mg} / \mathrm{ml})$, no significant differences were observed compared to the control sample on day 2. For $\mathrm{ZrO}_{2}$, an increased IL-8 synthesis was initially observed after 2 days, which was even higher with the lower particle concentration. After 4 days of incubation, a significant decrease in IL-8 expression was observed in the samples incubated with $\mathrm{ZrO}_{2}$ at a concentration of only $0.1 \mathrm{mg} / \mathrm{ml}$.

$V E G F$ and FGF. Following treatment with all bone cement particles, an increase in VEGF expression was observed. This increase was significant in the samples incubated with Palacos $(\mathrm{P}=0.02)$ and Cemex Genta $(\mathrm{P}=0.046)$ (both, $0.1 \mathrm{mg} / \mathrm{ml})$, as well as in those incubated with Simplex P $(0.01 \mathrm{mg} / \mathrm{ml} ; \mathrm{P}=0.017)$ after 2 days of incubation. After 4 days, concentration-dependent differences were observed with all used particles (Fig. 2). In the approach described, no expression of FGF was detected in the human osteoblasts.

$M C P-1$. For the expression of MCP-1, cement-specific differences were observed (Fig. 3). A significant, time-dependent decrease in MCP-1 concentration was observed with all bone cements used (Palacos $\mathrm{R}, \mathrm{P}=0.003$; Simplex $\mathrm{P}, \mathrm{P}<0.001$; Cemex Genta, $\mathrm{P}<0.001)$ at higher particle rates compared to the untreated control. Osteoblast cultures treated with $0.01 \mathrm{mg} / \mathrm{ml}$ Simplex $\mathrm{P}(\mathrm{P}=0.014)$ and Cemex Genta $(\mathrm{P}=0.012)$ expressed 

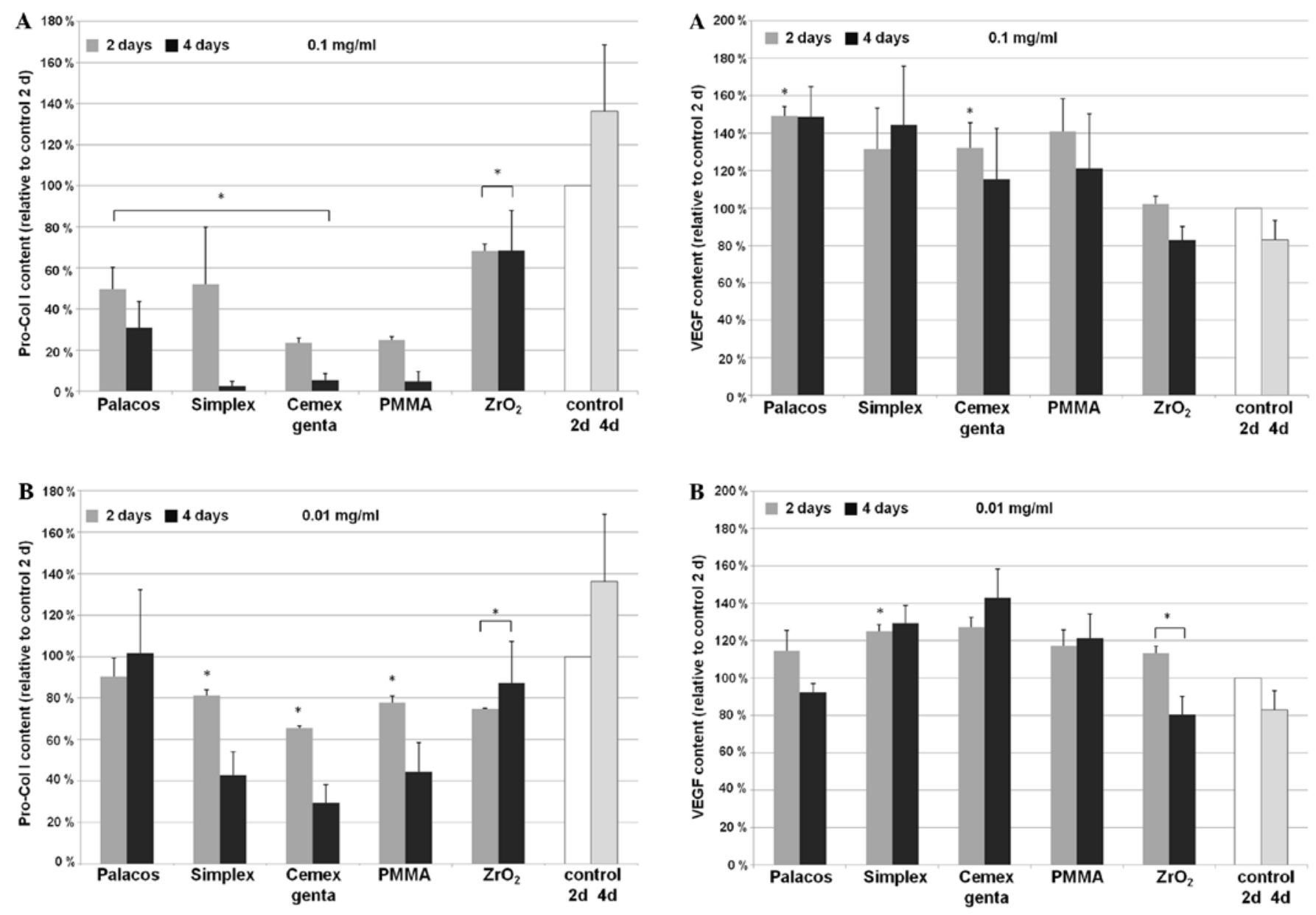

Figure 1. Synthesis of procollagen type I (Pro-Col I) in human osteoblasts following treatment with particles (A) $0.1 \mathrm{mg} / \mathrm{ml}$; (B) $0.01 \mathrm{mg} / \mathrm{ml} ; \mathrm{n}=3$. Supernatants were collected after 2 and 4 days of cultivation and analysed by ELISA. Data are presented as the mean values \pm SEM. Statistical analysis was performed using one-way ANOVA (post hoc LSD). Significance is based on the procollagen type I concentration of the control on day 2 ("P $<0.05)$. PMMA, polymethylmethacrylate; $\mathrm{ZrO}_{2}$, zirconium dioxide.

significantly lower MCP-1 levels after 4 days of incubation. Compared to the control, MCP-1 synthesis was not considerably increased following treatment with the particles.

Apoptosis and necrosis. The incidence of apoptosis and necrosis also differed depending on the type of cement and its concentration in the sample (Fig. 4). A high rate of apoptosis of human osteoblasts only occurred with high concentrations $(0.1 \mathrm{mg} / \mathrm{ml})$ of wear particles of Simplex P, Cemex Genta and PMMA powder $(\mathrm{P}<0.001)$. Cement-dependent differences were significant; Cemex Genta induced the highest rate of apoptosis, followed by PMMA and Simplex P (all, $\mathrm{P}<0.001)$. No significant difference in apoptosis were observed in the samples treated with all particle types at lower concentrations $(0.01 \mathrm{mg} / \mathrm{ml})$ compared to the control sample.

Apart from apoptosis, necrosis in the osteoblasts was detected following incubation with bone cement particles. This was particularly evident following incubation with Cemex Genta and PMMA powder (both, $\mathrm{P}<0.001$ ). No significant change in the rate of necrosis was observed in the samples treated with Simplex P, Palacos R and $\mathrm{ZrO}_{2}$ compared to the control sample.
Figure 2. Synthesis of vascular endothelial growth factor (VEGF) in human osteoblasts following treatment with particles (A) $0.1 \mathrm{mg} / \mathrm{ml}$; (B) $0.01 \mathrm{mg} /$ $\mathrm{ml} ; \mathrm{n}=3$. Supernatants were collected after 2 and 4 days of cultivation and analysed by Multiplex-ELISA. Data are presented as the mean values \pm SEM. Statistical analysis was performed using one-way ANOVA (post hoc LSD). Significance is based on the VEGF concentration of the control on day 2 $\left({ }^{*} \mathrm{P}<0.05\right)$. PMMA, polymethylmethacrylate; $\mathrm{ZrO}_{2}$, zirconium dioxide.

A comparison of absolute values of apoptosis and necrosis showed that human osteoblasts were more prone to apoptosis than necrosis following incubation with particles of Simplex P, PMMA and Cemex Genta.

\section{Discussion}

In the present experimental study, reactions specific to different bone cement particles were observed with respect to viability, collagen synthesis and cytokine expression in osteoblast cultures. According to Gough and Downes (16) bone cement particles can cause apoptosis in osteoblasts. Our research data underline these effects, whereas apoptosis following incubation with lower particle concentrations showed no effects. At higher concentrations, however, differences depending on the type of cement used were observed. It has been shown that higher concentrations of such particles in areas surrounding hip implants affect osteolysis (22). Palacos R particles showed the least pro-apoptotic potential. Our data were similar as regards the necrosis of osteoblasts; i.e., Palacos R revealed the least variation from the control sample. The other cement 

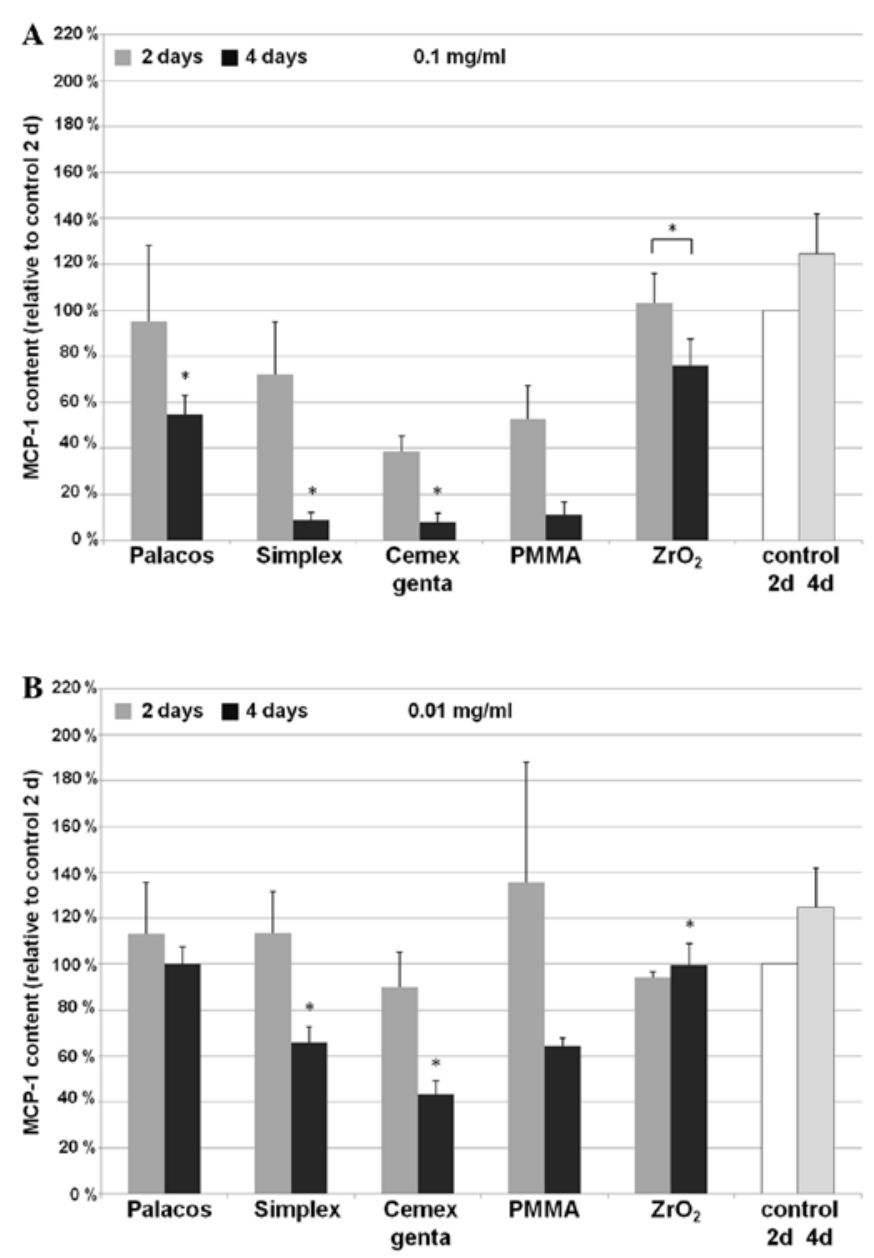

Figure 3. Synthesis of monocyte chemotactic protein-1 (MCP-1) in human osteoblasts following treatment with particles (A) $0.1 \mathrm{mg} / \mathrm{ml}$; (B) $0.01 \mathrm{mg} /$ $\mathrm{ml} ; \mathrm{n}=3$. Supernatants were collected after 2 and 4 days of cultivation and analysed by Multiplex-ELISA. Data are presented as the mean values \pm SEM. Statistical analysis was performed using one-way ANOVA (post hoc LSD). Significance is based on the MCP-1 concentration of the control on day 2 ( $\mathrm{P}<0.05)$. PMMA, polymethylmethacrylate; $\mathrm{ZrO}_{2}$, zirconium dioxide.

particle types showed increased necrosis at higher particle concentrations and affected osteoblast function more severely. If the capacity for collagen synthesis is also taken into account as an indicator of osteoblast viability, it becomes evident that cement particles have a particularly strong effect at higher concentrations. The concentration of cement particles is thus extremely important for cell reactions. A high particle concentration tends to be conducive to cellular processes that have a negative influence on osteoblast function and thus on the implant fixation in the bone stock. These aspects confirmed the findings of Lenz et al (20) who analysed the effects of metallic wear particles on the viability of osteoblasts. They found that $\mathrm{ZrO}_{2}$ ceramic particles did not negatively affect cell viability. This suggests that other components, such as bone cement particles have stronger effects on osteoblasts. Our experiments, as well as the findings of other research groups have demonstrated that PMMA exerts a negative effect on the viability of osteoblasts $(15,16)$. However, the cytotoxic effect is reduced following polymerisation (23). The PMMA content in polymerised bone cements varies insignificantly, and thus other factors must be taken into account (24). Analyses of the

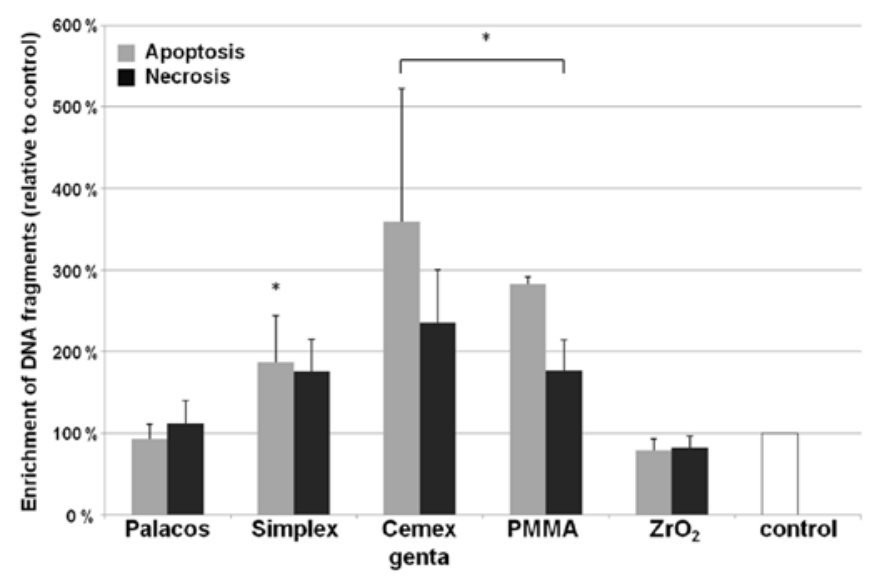

Figure 4. Quantification of human osteoblast apoptosis and necrosis following treatment with particles $(0.1 \mathrm{mg} / \mathrm{ml})$ on day 2 compared to the particle-free control $(n=3)$. Data are presented as the mean values \pm SEM. Statistical analysis was performed using one-way ANOVA (post hoc LSD). Significance is based on the control on day $2\left({ }^{*} \mathrm{P}<0.05\right)$. PMMA, polymethylmethacrylate; $\mathrm{ZrO}_{2}$, zirconium dioxide.

cements have revealed that the toxic residual monomer content in Simplex P and Cemex Genta is similar, but much higher than in Palacos R (24). This could be a cause of the observed cement-specific effects. The relevance of the radiopaque agent used must be taken into account as well. As regards the incidence of necrosis and apoptosis, in this study, no difference compared to the control sample was observed with cements containing $\mathrm{ZrO}_{2}$ as a radiopaque agent. However, we found elevated levels in cements containing barium sulphate $\left(\mathrm{BaSO}_{4}\right)$ as a radiopaque agent. $\mathrm{BaSO}_{4}$-containing cements showed a negative effect on procollagen type I synthesis in comparison with $\mathrm{ZrO}_{2}$. As regards cytokine expression, this difference only became apparent after a longer incubation time (4 days). In this case, a decline in cytokine release was observed with cements containing $\mathrm{BaSO}_{4}$ as a radiopaque agent. Gillani et al (25) demonstrated that $\mathrm{ZrO}_{2}$ has a more favourable effect on osteoblast cell density than $\mathrm{BaSO}_{4}$. The cytotoxic effect of the antibiotic, gentamicin, on osteoblasts is less relevant (26). Only in combination with $\mathrm{BaSO}_{4}$ does it amplify the triggered effect.

PMMA has been shown to exert a negative effect on osteoblasts $(15,16)$. In our study, this was only observed with higher particle concentrations. Since such concentrations may occur in situ after longer periods of time, it may be assumed that this effect does not substantially affect initial fixation but may well influence implant loosening at a later stage.

Cytokine-mediated osteolytic processes are relevant to aseptic implant loosening. The disruption of osteoblast viability causes a decreased capability of repair. An important aspect is cytokine expression. It is known that IL-6 positively affects the differentiation of osteoblast progenitor cells, has an anti-apoptotic effect and can stimulate the differentiation of osteoclasts (8). Following the addition of cement particles, the secretion of IL-6 is initially increased. The above-mentioned anti-apoptotic effect on osteoblasts can occur. Since there is a reduction in IL-6 after longer periods of time, particularly at higher particle concentrations, the anti-apoptotic effect may be negatively affected. Another signalling pathway may be involved in the activation of osteoclasts (8). A stronger 
expression of IL-6 has been observed with wear particles with a lower metal content (Simplex P and Cemex Genta). This suggests that the other components (e.g., $\mathrm{BaSO}_{4}$ and PMMA) have a greater influence on IL-6 expression.

Another factor that influences aseptic implant loosening is an increased expression of MCP-1 and IL-8. Both cytokines can stimulate the migration of macrophages and neutrophile granulocytes (4). In our study, for MCP-1, a decreased or rather the same synthesis rate in osteoblasts following treatment with the particles was observed compared to the untreated cells. These results are in agreement with those by Lochner et al (21) who analysed the expression rate of MCP-1 following treatment with metallic wear particles. Since osteoblasts are able to express MCP-1, and MCP-1 induction was not observed following treatment, they are therefore not associated with osteoclast differentiation by macrophage attraction (21). By contrast, IL-8 synthesis rates were initially increased following treatment with particles at higher concentrations. Hereby, an initially induced secretion by osteoblasts stimulated osteoclasts to migrate into the periprosthetic tissue (21). In agreement with the study by Lochner et al (21), it has been shown that IL-8 expression decreases with incubation time, as shown in the study by Fritz et al (27). These results suggest that osteoclast stimulation is associated with the early stages of aseptic implant loosening.

If the metal content of the cement wear debris is taken into account, it is evident that wear particles with a high metal content per unit of quantity cause a higher rate of cell death than those with a lower metal content (20). The relevance of the type of metallic wear components and the influence on viability and cytokine expression has been described in detail in our previous studies [Lenz et al (20) and Lochner et al (21)]. However, in our present study, a higher metal content in wear debris using Palacos $\mathrm{R}$ cement did not lead to an increased expression of cytokines or chemokines compared to the other bone cements examined. Furthermore, wear debris with a high metal content from Palacos $\mathrm{R}$ cement caused a lower rate of cell death compared to the other cements with a lower metal content (e.g., Cemex Genta, Simplex P). We assume that this effect is due to the fact that $\mathrm{ZrO}_{2}$ is the radiopaque agent in Palacos $\mathrm{R}$ cement. Hence, the effect of these agents $\left(\mathrm{ZrO}_{2}\right.$ vs. $\left.\mathrm{BaSO}_{4}\right)$ may be of greater importance than the metal content of the bone cement debris. The concentration and type of metal particles, however, is of significant relevance for the expression of procollagen and cytokines, even when identical bone cement is used. Lenz et al (20) demonstrated that wear particles with a high content of cobalt-chromium have a stronger negative impact on expression than wear particles containing titanium. The release of VEGF, which is necessary for angiogenesis, was generally increased as a reaction to the wear particles, with the exception of $\mathrm{ZrO}_{2}$. Angiogenesis helps by quickly bringing cellular defence to the region of interest $(7,28)$. Cement particles can also trigger this reaction. FGF, which is important in fracture healing and is usually produced by chondrocytes, is not synthesised by osteoblasts (7). Accordingly, we did not determine any FGF levels following treatment with the particles.

As previously described in the study by Ciapetti et al (18), cement particles lead to specific differences in terms of cell viability and cytokine production. Our data show that the content of PMMA, radiopaque agents and metallic particles are all relevant. The use of the antibiotic, gentamicin, intensified the observed effects of bone cement containing $\mathrm{BaSO}_{4}$. The content of PMMA in wear particles can thus be relevant to the biocompatibility of the bone cement used. A limitation of our present study was that the influence of residual monomer content and antibiotics was not examined separately. Hence, the effects of specific bone cement components should be the subject of further studies. It is known that the size and form of wear debris affects cellular reactions (3). Nevertheless, particle size and form were not analysed in the present study. Thus, no statement to a potential effect caused by an imbalance of particle size and form can be given. Moreover, we investigated the effect of the wear debris as a whole on osteoblasts. The different components within the wear debris (metal vs. bone cement) may have an effect on cell behaviour; therefore, an investigation of separate particles is recommended in future studies.

In conclusion, the type of wear particles is of great relevance for adverse biological and tissue reactions in the human body. Since particle concentration plays an important role, the amount of wear debris generated by cemented implants and the composition of wear particles are relevant influencing factors for the occurrence of osteolysis and subsequent aseptic loosening following total hip endoprosthesis.

\section{Acknowledgements}

We thank Ms. Susanne Finze for statistical analysis and Mr. Andreas Fritsche for the preparation of bone cement particles.

\section{References}

1. Herberts $\mathrm{P}$ and Malchau $\mathrm{H}$ : Long-term registration has improved the quality of hip replacement: a review of the Swedish THR Register comparing 160,000 cases. Acta Orthop Scand 71: 111-121, 2000.

2. Bader R, Steinhauser E, Holzwarth U, Schmitt M and Mittelmeier W: A novel test method for evaluation of the abrasive wear behavior of total hip stems at the interface between implant surface and bone cement. Proc Inst Mech Eng H 218: 223-230, 2004.

3. Hallab NJ and Jacobs JJ: Biologic effects of implant debris. Bull NYU Hosp Jt Dis 67: 182-188, 2004.

4. Ingham $E$ and Fisher J: Biological reactions to wear debris in total joint replacement. Proc Inst Mech Eng H 214: 21-37, 2000.

5. Queally JM, Devitt BM, Butler JS, Malizia AP, Murray D, Doran PP and O'Byrne JM: Cobalt ions induce chemokine secretion in primary human osteoblasts. J Orthop Res 27: 855-864, 2009.

6. Emes Y, Aybar B, Vural P, Saral NY, Atalay B, Kaya AS, Issever $\mathrm{H}$, Yalcin $\mathrm{S}$ and Bilir A: Effects of bone morphogenetic proteins on osteoblast cells: vascular endothelial growth factor, calcium, inorganic phosphate, and nitric oxide levels. Implant Dent 19: 419-427, 2010.

7. Schmid GJ, Kobayashi C, Sandell LJ and Ornitz DM: Fibroblast growth factor expression during skeletal fracture healing in mice. Dev Dyn 238: 766-774, 2009.

8. Kwan Tat S, Padrines M, Théoleyre S, Heymann D and Fortun Y: IL-6, RANKL, TNF-alpha/IL-1: interrelations in bone resorption pathophysiology. Cytokine Growth Factor Rev 15: 49-60, 2004.

9. Neale SD, Sabokbar A, Howie DW, Murray DW and Athanasou NA: Macrophage colony-stimulating factor and Interleukin-6 release by periprosthetic cells stimulates osteoclast formation and bone resorption. J Orthop Res 17: 686-694, 1999.

10. Chiu R, Ma T, Smith RL and Goodman SB: Ultrahigh molecular weight polyethylene wear debris inhibits osteoprogenitor proliferation and differentiation in vitro. J Biomed Mater Res A 89: 242-247, 2009. 
11. Olivares-Navarrete R, Raines AL, Hyzy SL, Park JH, Hutton DL, Cochran DL, Boyan BD and Schwartz Z: Osteoblast maturation and new bone formation in response to titanium implant surface features are reduced with age. J Bone Miner Res 27: 1773-1783, 2012.

12. Mitchell W, Bridget Matthews J, Stone MH, Fisher J and Ingham E: Comparison of the response of human peripheral blood mononuclear cells to challenge with particles of three bone cements in vitro. Biomaterials 24: 737-748, 2003.

13. MacQuarrie RA, Fang Chen Y, Coles C and Anderson GI: Wearparticle-induced osteoclast osteolysis: the role of particulates and mechanical strain J Biomed Mater Res B Appl Biomater 69: 104-112, 2004.

14. Sun J, Lin F, Hung T, Tsuang Y, Chang WH and Liu HC: The influence of hydroxyapatite particles on osteoclast cell activities. J Biomed Mater Res 45: 311-321, 1999.

15. Zambonin G, Colucci S, Cantatore F and Grano M: Response of human osteoblasts to polymetylmetacrylate in vitro. Calcif Tissue Int 62: 362-365, 1998.

16. Gough JE and Downes S: Osteoblast cell death on methacrylate polymers involves apoptosis. J Biomed Mater Res 57: 497-505, 2001.

17. Willert HG, Ludwig J and Semlitsch M: Reaction of bone to methacrylate after hip arthroplasty: a long-term gross, light microscopic, and scanning electron microscopic study. J Bone Joint Surg Am 56: 1368-1382, 1974.

18. Ciapetti G, Granchi D, Cenni E, Savarino L, Cavedagna D and Pizzoferrato A: Cytotoxic effect of bone cements in HL-60 cells: distinction between apoptosis and necrosis. J Biomed Mater Res 52: 338-345, 2000.

19. Ciapetti G, Granchi D, Savarino L, Cenni E, Magrini E, Baldini $\mathrm{N}$ and Giunti $\mathrm{A}$ : In vitro testing of the potential for orthopedic bone cements to cause apoptosis of osteoblast-like cells Biomaterials 23: 617-627, 2002.
20. Lenz R, Mittelmeier W, Hansmann D, Brem R, Diehl P, Fritsche A and Bader R: Response of human osteoblasts exposed to wear particles generated at the interface of total hip stems and bone cement. J Biomed Mater Res A 89: 370-378, 2009.

21. Lochner K, Fritsche A, Jonitz A, Hansmann D, Mueller P, Mueller-Hilke B and Bader R: The potential role of human osteoblasts for periprosthetic osteolysis following exposure to wear particles. Int J Mol Med 28: 1055-1063, 2011.

22. Hirakawa K, Bauer TW, Stulberg BN, Wilde AH and Secic M: Characterization and comparison of wear debris from failed total hip implants of different types. J Bone Joint Surg Am 78: 1235-1243, 1996.

23. Ciapetti G, Stea S, Granchi D, Cavedagna D, Gamberini S and Pizzoferrato A: The effects of orthopaedic cements on osteoblastic cells cultured in vitro. Chir Organi Mov 80: 409-415, 1995.

24. Kühn KD: Knochenzemente für die Endoprothetik. SpringerVerlag, Berlin, 2001.

25. Gillani R, Ercan B, Qiao A and Webster TJ: Nanofunctionalized zirconia and barium sulfate particles as bone cement additives. Int J Nanomedicine 5: 1-11, 2010.

26. Rathbone CR, Cross JD, Brown KV, Murray CK and Wenke JC: Effect of various concentrations of antibiotics on osteogenic cell viability and activity. J Orthop Res 29: 1070-1074, 2011.

27. Fritz EA, Glant TT, Vermes C, Jacobs JJ and Roebuck KA: Titanium particles induce the immediate early stress responsive chemokines IL-8 and MCP-1 in osteoblasts. J Orthop Res 20: 490-498, 2002

28. Bernardini G, Ribatti D, Spinetti G, Morbidelli L, Ziche M, Santoni A, Capogrossi MC and Napolitano M: Analysis of the role of chemokines in angiogenesis. J Immunol Methods 273: 83-101, 2003. 